América sin Nombre, n. ${ }^{\circ} 21$ (2016): 59-71

DOI: 10.14198/AMESN.2016.21.04

ISSN: 1577.3442 / eISSN: 1989-9831

Fecha de recepción: 10/09/2016

Fecha de aceptación: 04/11/2016
Puede citar este artículo como:

Hernández Araico, Susana. "Monarquía y montaje en las loas de Sor Juana». Teatro breve virreinal. Miguel Zugasti (coordinador). América sin Nombre, 21 (2016): 59-71, DOI: 10.14198/AMESN.2016.21.04

Link para este artículo: http://dx.doi.org/10.14198/AMESN.2016.21.04

\title{
Monarquía y montaje en las loas de Sor Juana
}

\author{
The Monarchy in the Staging of Sor Juana's Loas
}

\author{
Susana Hernández Araico* \\ California State Polytechnic University, Pomona \\ Profesora Emérita
}

\section{Resumen}

La alabanza de la monarquía resalta de modo significativo en la trayectoria literaria de Sor Juana desde su primer poema publicado preconventualmente hasta un texto mencionado (aún no encontrado) en la Fama póstuma. El doble montaje de sus siete loas a los monarcas - escenificación virreinal y publicación en Espańa- está estrechamente vinculado a la ubicación de los virreyes dentro de la política de la corte madrileńa.

Palabras clave: Sor Juana, loas, monarquía, política, virreyes, escenificación, publicación.

\begin{abstract}
In Sor Juana's literary career, from her first published pre-convent poem up to a text mentioned (not yet found) in the Fama póstuma, praise for the monarchy plays a significant role. The double presentation of her seven preludes in honor of the monarch -the staging in New Spain and the publication in Spain- is closely linked to the position of the viceroys within the politics of the royal court in Madrid.
\end{abstract}

Keywords: Sor Juana, preludes, monarchy, politics, viceroys, staging, publication.

Las loas de fiestas reales a fines del XVII culminan en las de Sor Juana de homenaje a Carlos II, su reina consorte francesa y la reina madre, como introductorias piezas de teatro breve palaciego con sofisticadas alegorías mitológicas y música cantada del más alto nivel (Hernández Araico 1992, 2012, 2014), si bien sus acotaciones se limitan a los recursos de teatro comercial (Hernández Araico 2015, 66-67; 2009, 150-151), sin escenario de perspectiva, telón de boca, ni bastidores como en el Coliseo del Buen

* Originaria de Ensenada, Baja California, México; doctorado de la Universidad de California en Los Ángeles; especialista en teatro, principalmente de Calderón y de Sor Juana; Profesora Emérita de California State Polytechnic University, Pomona; profesora visitante en universidades de EE.UU., Canadá y España. Ha sido presidente de la Modern Language Association del Pacífico, directora del Instituto de Verano de Lengua y Cultura Hispánicas de la Universidad de California en Santa Bárbara, y vicepresidente en Norteamérica de la Asociación Internacional de Teatro Español y Novohispano de los Siglos de Oro. Ha publicado numerosos ensayos y reseñas en revistas prestigiosas y dictado comunicaciones y conferencias en congresos y universidades de Canadá, Europa, Estados Unidos e Hispanoamérica. Participa en consejos editoriales de revistas importantes y en mesas directivas de organizaciones culturales de la ciudad de Los Angeles, California. 
Retiro $^{1}$. Entre la producción artística de Sor Juana, sus loas por mucho tiempo pasaron casi desapercibidas, como bien lamentaba Méndez Plancarte (LXIII), contraponiéndose a los comentarios despectivos de Cotarelo y Mori sobre la producción de loas en los virreinatos (XL y XLIV). Pero en la década de 1980 importantes críticos (Paz, Daniel, Sabat de Rivers ${ }^{2}$ ) empiezan a llamar la atención sobre varios aspectos del teatro breve de la monja jerónima con distintos juicios valorativos. A medida que las loas de Sor Juana comienzan a cobrar su merecida atención crítica, las sacramentales que preceden a sus tres autos son objeto de mayor estudio (Bravo Arriaga, Sabat de Rivers 1992, Hernández Araico 1994, 1996a) que las llamadas «sueltas» ${ }^{3}$ (Méndez Plancarte LXXXV). Paralelamente, crece también el interés por las dos profanas de homenaje a virreyes publicadas con sus comedias, pues para Los empeños de una casa, desde 1725 por fin se incluye la loa en las ediciones de Salceda, García Valdés y Hernández Araico, y lo mismo cabe decir para Amor es más laberinto en las ediciones de Salceda y García Valdés. Pero esta que "parece precedió a la comedia que se le sigue» (Sor Juana, Segundo volumen, 378), llama la atención por dudarse de que efectivamente hubiera precedido a la segunda comedia de Sor Juana, y por la presencia de uno de los dos virreyes destinatarios -el Conde de la Monclova- en cuyo honor también en el mismo año se compuso otra loa para su entrada a Lima (Hernández Araico 1996b; 2001; 2005, 138139, 145; Zugasti 2014, 139-140).

De las doce loas «sueltas» profanas estudiadas por Rivera Krakowska -excluyendo, pues, la religiosa a

1. Véase el montaje de sendas loas de Calderón para Andrómeda y Perseo (Varey) y para Fieras afemina amor (Neumeister 237-244).

2. Aunque Sabat de Rivers señala entonces que «los personajes [de las loas de Sor Juana] son los mismos que se venían usando desde Calderón: mitológicos y de alegorías muy variadas», al destacar su intertextualidad con Salazar y Torres erróneamente refuerza el estereotipo de restrictiva religiosidad calderoniana: «En Sor Juana priva, en las loas también lo intelectual, más cerca de Calderón que de Salazar y Torres, sin estar, como aquél, atada a lo religioso» (52). Aparte de autos sacramentales y comedias de tema "religioso", el gran repertorio calderoniano de teatro profano incluye loas para fiestas reales que serían modélicas para dramaturgos contemporáneos, incluso para Sor Juana.

3. En todos estos trabajos se incluye extensa bibliografía sobre la Loa a El divino Narciso que sigue creciendo aun después de culminar en la edición de auto y loa de Robin Ann Rice (2005). la Concepción-, las cinco de homenaje virreinal suscitan variados enfoques (Bravo Arriaga; Hernández Araico 1992; Poot Herrera 1995, 2007; Velazco), mientras que poca crítica se concentra en las siete restantes de homenaje monárquico (Castro López; Daniel 1989; García Valdés). La composición de las doce loas profanas «sueltas» se da junto con otras obras literarias de Sor Juana en unos prolíficos quince años $(1675-1690)^{4}$, e incluye las mencionadas siete a la monarquía, cinco al rey Carlos II y dos más a sendas reinas del momento: la primera consorte María Luisa de Orleans y la reina madre Mariana de Austria. No obstante el desaire absoluto de Cotarelo, estas siete loas de Sor Juana a la monarquía forman parte culminante del desarrollo de «loas de fiestas reales» impulsado en la segunda mitad del siglo XvII por dramaturgos como Solís, Moreto, Calderón, Salazar y Torres y Bances Candamo (Cotarelo y Mori XXXII-XL) ${ }^{5}$. Por eso el análisis de las loas monárquicas de la jerónima se debe abordar dentro de su intertextualidad con la estilística alegórica-mitológica-musical impuesta por tales dramaturgos en la corte madrileña. Las de Sor Juana no tienen nada que ver con los largos monólogos en verso llamados «loas» y recitadas por un(a) farsante o comediante para la explicación de un arco o incluso por una dama para festejar el Sacramento (María y Campos 83, 89, 91-92; Méndez Plancarte XI) ${ }^{6}$, ni con las que «repetidas veces se alude... a arengas en fiestas públicas» en la Nueva España (Schilling 146). Que las loas para teatro comercial y sacramental fueran acomodaticias, con final fácilmente adaptable para prologar cualquier comedia o auto o para presentar una compañía en distintas ciudades -y en ese sentido independientes por intercambiables, como

4. Las fechas de las loas sorjuaninas provienen de la edición de Méndez Plancarte.

5. «Se encuentran en casi todas las numerosas listas consultadas [de embarque de libros para las Indias]... los autos sacramentales de Calderón, con sus comedias, y las de Lope de Vega, Antonio de Solís, Juan Bautista Diamante, Francisco de Rojas y Juan Pérez de Montalván» (Torre Revello 11). Asimismo, las comedias de Salazar y Torres se representan en el coliseo en 1677-1679 (María y Campos 95 y 98). Como nos consta también que Bances Candamo leyó el Segundo volumen de la monja jerónima $(94 ; 132$, n. 86), habría que examinar sus loas posteriores a 1692 para cualquier rastro sorjuanino.

6. Toussaint tildó de «loa» el poema ekfrástico «Explicación sucinta del arco triunfal... en la feliz entrada del... Marqués de la Laguna... que hizo la Madre Juana Inés de la Cruz», texto que en realidad «se recitó o leyó ante el arco durante el espectáculo» (Arenal 45). 
«verdaderos comodines» (Rull 1989)- no significa que estas loas se concibieran para representación autónoma.

De la tesis doctoral de Meredith de treinta años atrás ${ }^{7}$, Méndez Plancarte (LII) parece tomar la observación de que, con Agustín de Rojas, «la loa recibe plena autonomía, no solo como pieza separada de la mayor, sino como dotada ya de asunto propio y distinto", opinion que repiten Sabat de Rivers (1982, 49), Daniel $(1977,144-46 ; 1983,21,33)^{8}$ y García Valdés (122). Sin definir con precision el calificativo «sueltas» que aplica a las «otras» trece loas de Sor Juana publicadas sin acompañar auto o comedia, Méndez Plancarte incluso llega a llamarlas «autónomas» $(\mathrm{X})$, a pesar de que en tres casos comenta el documentado acompańamiento de una comedia: por referencia histórica como en la primera loa para el cumpleańos del rey o como en la segunda "Al mismo asunto" (Inundación castálida fols. 100-108; ed. Méndez Plancarte, vv. 485-505) y en la escrita «al año [...] del primogénito» (ed. Méndez Plancarte, vv.420428), por imbricación con la comedia a seguir hacia el final de la loa misma. El insigne editor sorjuanista no reconoce que las Otras Loas «son 'sueltas' solo en cuanto se desconozca la comedia que introducen y que en principio, no se las puede concebir 'autónomas' por su función teatral de prólogo» (Hernández Araico 1992, 141), aunque no expresen vínculo alguno con la comedia o celebración que introducen. Por ejemplo, la «Loa para los años del emperador de Alemania», de Moreto de 1653, Lobato no la llama «suelta» ni «independiente», y observa "que precedió a una comedia, sin que sea posible determinar su título» (2003, I, 125). Los cumpleaños monárquicos se celebran teatralmente con mucho más, pues, que una pieza breve de alabanza.

De manera que tampoco puede contemplarse que las loas de Sor Juana para tales ocasiones «en muchos casos debieron constituir el núcleo del espectáculo» (García Valdés 122) por el hecho de referirse a un «pequeño festejo». Tal expresión de modestia

7. Después de citar del Al lector del Viaje entretenido de Rojas, Meredith (134) concluye en su tesis doctoral: "The loa had attained not only literary but economic independence».

8. Este mismo autor, en otro trabajo suyo $(1989,78)$ insiste en la independencia de la mayoría de las loas sin comedia identificada a continuación y en la contribución de Sor Juana a este género breve precisamente por el desarrollo de su independencia: «Seguramente algunas de las loas independientes de Sor Juana se montaron como comedias de un solo acto («one act plays»). no puede interpretarse como referencia a su pieza breve como celebración teatral completa. Así como al referirse al senado y a las damas del auditorio en el remate de varias loas, Sor Juana acude a convenciones establecidas ${ }^{9}$, al aludir a, o incluso pedir perdón por, la «cortedad» de varias de sus loas ${ }^{10}$, igualmente recurre a una convención teatral, la clásica expresión de captatio benevolentiae. Señala «la cortedad» de sus piezas breves rebajándose modestamente ante los homenajeados reales lejanos, así como ante los virreyes y toda la corte virreinal presente, con el fin de ensalzar aún más la grandeza de todo su público palaciego ${ }^{11}$. Como loas para fiestas reales de dramaturgos españoles contemporáneos, las loas monárquicas de Sor Juana tampoco constituyen un festejo teatral completo en sí. Y aunque pueda haber raras excepciones para celebraciones callejeras o al'aperto para público masivo ${ }^{12}$, acertadamente afirma Rivera Krakowska (128) que, como «en las representaciones

9. Algo así como "perdonad, noble senado, sus muchas faltas» es la consabida frase hecha al final de comedias para congraciarse el dramaturgo y «autor» (director de compañía) con su público en general; al final de las loas de Sor Juana, «senado» no se refiere, pues, a la Audiencia de México (Méndez Plancarte III: 698, n. a vv. 659-62; Castro López 115-116), aunque probablemente sus miembros presenciaran el espectáculo. En la "Loa para El amor más desgraciado, Céfalo y Pocris», de Salazar y Torres, el personaje Febrero aclara la convención de saludar a las damas de palacio al final de una loa: «Tengan, que falta también / según uso palaciego, / pedir la venia a las damas» (vv. 227-229).

10. Véanse las Loas al rey I: vv. 367-68 y 379; III: vv. 386-87; y la IV: v. 589; además la loa a la reina consorte: «perdonad la cortedad» (v. 254) y la loa a la reina madre: "corto obsequio» (v. 243).

11. La relatividad de grandeza en el homenajeado y pequeńez del modesto homenaje sorjuanino (que crece en manos de las damas de la Condesa) se aclara en la loa al virrey, donde Sor Juana le ofrece a la virreina el obsequio de la loa que "como vuestro, / solo podrá ser digno / de vuestro excelso esposo. / [...] Vuestras Damas os lo ofrecen / con tan rendido afecto, / que pareciera grande / al no excederlo el Dueño» (vv. 504-513).

12. Zugasti $(2002,198)$ aclara: «A finales del xviI, y de forma muy excepcional, hay algunos casos donde la loa se convierte en la parte central y casi única del espectáculo, sin más aditamentos dramáticos: Festivo aparato (México, 1672) para celebrar la canonización de S. Francisco de Borja; Festejo y loa (Madrid, 1690) en regocijo por el feliz arribo de la reina Mariana [de Neoburgo] a España». Otro ejemplo quizá sería la pieza editada por el mismo Zugasti (2014, 141-152): «Loa a la entrada del virrey Conde de la Monclova en Puebla de Los Ángeles (1686)», pues de hecho no se hizo ninguna comedia a continuación. 
cortesanas, tan del gusto de Felipe IV y Carlos II [...], la loa precedía invariablemente al festejo»; es decir, en principio para público de nobles, dentro de sitios reales o recintos virreinales, incluso jardines.

Si bien el montaje de los breves encomios teatrales de Sor Juana a los reyes carecía en el palacio virreinal de los últimos recursos escénicos que Fontana, Lotti y Baccio del Bianco despliegan en las fiestas del Buen Retiro, la poesía dramática de la jerónima acota movimientos y gesticulación para los actores-criados de la corte que, con ayuda de vistosos trajes, iluminación y hermosa música cantada, habrá producido gran impacto visual. No se trata de la imaginería poética, aunque de gran logro ${ }^{13}$, sino de teatro, del movimiento de bajadas y subidas, así como salidas paralelas con el énfasis kinésico-actoral de los parlamentos donde Sor Juana otorga fuerza dramática a cada personaje. Pero aparte del montaje escénico de los homenajes teatrales de Sor Juana a los reyes, amerita examinar las implicaciones publicitarias de su producción novohispana así como de su montaje impreso español. De las siete loas sorjuaninas de celebraciones reales, solo cuatro de las cinco dedicadas al rey y la de homenaje a la reina francesa aparecen en Inundación castálida (1689), mientras que las dos restantes -la tercera dedicada al rey y la de homenaje a la reina madre- se publican en el Segundo volumen (1692). Incumbe preguntarse ¿por qué incluir en Inundación castálida la loa de cumpleaños a María Luisa de Orleans (escrita en 1681, 1682 o 1683) ${ }^{14}$, si la reina francesa había muerto en febrero, meses antes de las licencias de esa publicación en agosto y septiembre, cuando además ya se ha llevado a cabo por poderes el segundo matrimonio de Carlos II con Mariana de Neoburgo? ¿Y por qué dejar fuera una de las loas a Carlos II, la tercera, que se imbrica en posible fecha de composición y montaje con la segunda de 1681-1682? Queda reservada para el Segundo volumen de 1692, donde también figura la loa a los años de la reina madre, Mariana de Austria, y donde brillaría por su ausencia homenaje alguno de Sor Juana y de sus virreyes a la segunda reina consorte, tocaya de la madre del rey. Pues obviamente no se le comisionó nada para Mariana de Neoburgo, si bien bajo el Conde de Galve Sor Juana por fin había

13. Para García Valdés (121), en contraposición al teatro «sobresaturado de efectos escénicos» en la metrópoli, «Sor Juana mantiene el poder evocador de la palabra y el canto que recrean una escenografía verbal».

14. Para montajes cortesanos madrileńos durante el reinado de María Luisa de Orleans, véase Lobato, 2007. compuesto dicha loa de homenaje a la reina madre entre $1688-1690^{15}$.

La celebración en la corte virreinal de los cumpleaños de Carlos II, de su primera consorte francesa y de la reina madre que se conmemora en las loas de Sor Juana, está estrechamente ligada a la política de la metrópoli y la postura de los virreyes en ese enjambre de intrigas en torno al manipulable rey minusválido, el medio hermano (bastardo reconocido) don Juan José de Austria, la madre austríaca de la familia imperial, la reina francesa (sobrina de Luis XIV) y la generalmente detestada alemana del Palatinado ${ }^{16}$. Los virreyes Marqués de la Laguna y Condesa de Paredes -casados en palacio unos días después de adquirir su mayoría y el trono el endeble Carlos IImantienen relación complicada con la corona; pues la Condesa había sido menina de la Infanta Teresa (reina consorte de Luis XIV desde 1660) y después dama de la reina madre Mariana, mientras que el hermano del Marqués, el Duque de Medinaceli, no favorecía la continuación del poderío de esta, una vez lograda la mayoría del rey en 1675 . En medio de la cuestión más candente de Europa, la sucesión al trono de España (tema aludido en las loas de Sor Juana a Carlos II y a la reina consorte), Medinaceli apoya a don Juan José en la selección de esposa francesa en vez de austríaca y, durante el gobierno del hijo bastardo de Felipe IV (1677-1679), llega a incorporarse a su círculo más íntimo de tal manera que lo sucede como ministro. El nombramiento de su hermano como virrey de la Nueva España puede haber sido un acuerdo político con la reina de alejarlo, dada la falta de compromiso con ella por parte del Marqués, a pesar de la cariñosa relación de la Condesa de Paredes con la reina madre. Pero cuando los virreyes vuelven a España, las loas de Sor Juana al rey incluidas en Inundación castálida constituyen no solo prueba impresa de su indudable lealtad a la corona, sino de gratitud al rey por el otorgamiento de la grandeza de España al Marqués de la Laguna en 1687, celebrado precisamente en junio de 1689. La tercera Loa de Sor Juana al rey que no incluye homenaje a la reina madre -como la segunda, cuarta y quinta-, se deja conspicuamente fuera quizá por

15. El Conde de Galve había asistido en la preparación de festejos cortesanos al ministro de Mariana, Valenzuela, el "duende», cuyo exilio concluye en México bajo la protección del virrey.

16. Las observaciones sobre política en las siguientes secciones están basadas en Maura y Gamazo, Paz, Ortuño, Ruiz Rodríguez, Sabat de Rivers (1998) y Sicard. 
su ambivalente imaginería solar; la falta de alusión a la reina madre en la primera loa que encabeza la serie de cuatro en Inundación se justificaría por celebrar la mayoría de edad del rey. La Loa a los años de la reina María Luisa de Orleans en su montaje escénico en la Nueva España manifestaría la política del Duque de Medinaceli y de su hermano el virrey, inclinada hacia Francia, en oposición a las maniobras de la reina madre para la sucesión austríaca ${ }^{17}$, si bien la loa no deja de homenajear tanto a Mariana como al rey. En su publicación, los últimos tres meses de 1689 -casado ya el rey por poderes en segundas nupcias con Mariana de Neoburgo-, ¿funcionaría la loa a la reina francesa muerta como advertencia de la oposición a ambas reinas Marianas por parte del sucesor de Medinaceli, el Conde de Oropesa y su partido? ¿O pretendería hostigar solo a la joven consorte que pronto rivalizaría la política austríaca de la reina madre? ${ }^{18}$ Por otro lado, el nombramiento del Marqués de la Laguna como mayordomo de la reina de Neoburgo en 1689, ¿le serviría al nuevo valido Oropesa para aparentar congraciarse con ella y a la vez ejercer mayor control sobre sus maniobras en la corte?

En cuanto al Segundo volumen de 1692, con licencias de julio de ese año, las dos loas monárquicas de Sor Juana servirían a la Condesa de Paredes para resolidificar su posición en la corte una vez que el otorgamiento de grandeza de España a ella, en el mes de abril del mismo ańo que muere el Marqués, le permite tornar al seno palaciego de la reina madre. En la Loa tercera se reafirma su homenaje al rey, mientras que, una vez fallecido el Marqués, su personificación como Sol en esa loa serviría de veneración fúnebre sin restar nada a la luminosidad regia del monarca. La inclusión de la tercera Loa a los años del

17. Castro López considera la política europea en torno a esta loa a la reina consorte francesa.

18. Muestra de afecto para la reina Mariana, dada su consabida práctica devota, habrá sido la inclusión del soneto de homenaje a la devoción eucarística de Carlos II (Méndez Plancarte I: 303, 543), dentro de la tradición imperial austríaca; de 1685 o 1686, había quedado fuera del «opúsculo» de Sonetos de ingenios de esta corte (evidentemente reservado para compilación posterior de la Condesa de Paredes); sobre el mismo asunto de las mismas fechas sería el texto que Castorena cita como inédito en su «Prólogo a quien leyere» de la Fama y obras póstumas: "Glosa en décimas a la ínclita religiosa acción de nuestro católico monarca (que Dios guarde) en haber cedido el trono a la Divina Majestad Sacramentada». rey que no menciona a la reina madre, aunque sí muy especialmente aún a la reina francesa, se compensa con la loa dedicada especialmente a aquélla. Aunque no comisionada por la Condesa pero obviamente incluida en el Segundo volumen por decision suya, esta loa constituye una muestra no solo de afecto por la reina madre, sino también de agradecimiento por reincorporarla a su círculo cortesano. Dos años después, en 1694, la reina solicita a la Condesa, quien años atrás había sido su dama, como camarera mayor.

Sor Juana misma no tiene nada que ver personalmente con todas estas intrigas de la corte madrileńa y su política europea - de la cuales quizá estaría bastante enterada-; pero la publicación de sus loas monárquicas en 1689 y $1692^{19}$-su montaje impreso-, funciona a manera de ofrenda de piezas que los ex-virreyes utilizan como obsequios de agradecimiento al rey y a la reina madre ${ }^{20}$. La comisión de las loas monárquicas de Sor Juana, su montaje escénico para celebración palaciega virreinal, así como su publicitario montaje impreso en España, se vinculan inextricablemente a la ubicación política de sus patrocinadores virreinales en los enmarañados sucesos de la corte madrileńa y el candente asunto de la sucesión española que aflora en las loas. Las dos publicaciones de 1689 y 1692 cumplen entonces propósitos personales-políticos de la Condesa de Paredes y su marido que habrían de caer en el olvido, mientras que documentan y difunden perdurablemente por todo y plus ultra del imperio español los admirables logros literarios-poéticosdramáticos de Sor Juana. En sus loas de homenaje al rey y a las dos reinas se ve entonces la manifestación teatral del encomio monárquico sorjuanino que figura de manera muy significativa a través del progresivo ascenso de la Fénix mexicana a la cúspide de su reconocimiento.

El homenaje a la monarquía por parte de Sor Juana data desde «su primera poesía fechable» (Méndez Plancarte I: 539), el soneto «A la muerte del señor rey Felipe IV» de 1666, poco después de llegar en mayo a la Nueva España la noticia de haber muerto el rey en septiembre del año anterior. Este "público lucimiento de la precoz escritora» sin duda encariñaría aun más a la adolescente Juana con la

19. Inundación castalida se repite como Primer tomo en 1691.

20. En este sentido también deben considerarse las loas sacramentales de Sor Juana para El divino Narciso y El mártir del Sacramento que rematan en homenaje monárquico (Hernández Araico 1998, 258-259) y ejemplifican lo que Rull (1994) llama «la función teológica-política de la loa» en algunos autos calderonianos. 
virreina Mancera que "con orgullo la exhibiría como poeta de la corte durante el pésame de las autoridades civiles y religiosas» en junio, así como durante la alegre ceremonia de la jura de Carlos II y la otra «luctuosa... ante el impresionante túmulo construido en la catedral» en julio. El talento poético de la preconventual joven Sor Juana empieza entonces a suscitar el desagrado de su muy próximo director espiritual por iniciar su fama dentro del ámbito cortesano (Martínez López 142-143), concretamente con un homenaje a la monarquía.

Casi una década después, para otra ocasión cortesana sobresaliente, la jerónima retoma el encomio del soberano en su primera Loa en celebración de los años del rey nuestro señor, con la cual incursiona en la arena pública-oficial-cortesana con temática profana, estrenando la dramaturgia de loas en boga, alegórica-musical-mitológica ${ }^{21}$. Alatorre $(2010,270)$ ha observado que "hasta 1680 Sor Juana no había sido conocida sino por los villancicos». Pero además, antes del Neptuno alegórico, Sor Juana exhibe su talento en la Loa de la Concepción que Méndez Plancarte (III: 651) fecha entre 1670-1675 y que probablemente precede a la primera Loa en celebración de los años del rey nuestro señor, fechada entre 1674-1678 por Salceda (344), pero más específicamente por Méndez Plancarte en 1675 (III: 653). Pues hacia fines de la Loa, Sor Juana interrumpe su homenaje al rey con un apóstrofe a fray $\mathrm{Payo}^{22}$ para agradecer la prorrogación de su virreinato, una vez anulados con gran alegría (Robles I: 182) dos avisos anteriores de nuevo virrey a fines de agosto y principios de septiembre de 1675 (Robles I: 180-181). A la vez Sor Juana alaba a su protector obispal: "con las dichas de serviros / las glorias de poseeros. / Gocémoslas; y aunque el mar / surquen más alados leños, /nunca nos traigan más nueva / que de gozaros de nuevo» (vv. 360-365) ${ }^{23}$. Sin sospechar el provechoso futuro que se le esperaba bajo el anunciado pero postergado "Conde de Paredes» (Robles I: 180), Sor Juana aprovecha celebrar la retención de fray Payo como virrey dentro de su Loa para ocasión monárquica grandiosa.

21. Véase Hernández Araico, 2012 y 2014.

22. Llamada por Méndez Plancarte (III: 292) «Alocución al Arzobispo Virrey", pero sin tal encabezado divisivo en Inundación castálida (fols. 91v-92).

23. Todas las citas de loas, indicadas por versos, provienen de la edición del vol. III de Méndez Plancarte; se indicarán divergencias con su publicación en Inundación castálida o en el Segundo volumen.
Si bien esta primera Loa para el cumpleaños de Carlos II Méndez Plancarte la fecha más específicamente que Salceda por celebrar a la vez la prorrogación del virreinato de fray Payo en 1675, no se ha reconocido que Sor Juana la habrá compuesto por la enorme resonancia de este cumpleaños real en particular. Pues en ese año Carlos II llega a su mayoría, la edad de catorce años que el testamento de Felipe IV estipulaba para que gobernara. No se ha hecho la conexión entre esos dos datos, es decir, que la primera Loa al rey, evidentemente de 1675 por mencionar la prorrogación virreinal de fray Payo, Sor Juana debió componerla con motivo de la mayoría de edad del rey, comisionada e impulsada por su protector mismo, el obispo virrey, primo no solo del venidero virrey sino también del Duque de Medinaceli, partidario de don Juan José de Austria en intentar librar al rey del control de la reina madre regente y el odiado ministro Nithard. La ocasión exigía grandiosa celebración a través del imperio español por la mayoría de edad de Carlos II. La nobleza española en particular celebraba que se redujera el poder de la controvertida camarilla austríaca de la reina Mariana.

Así pues, para el cumpleaños de la reina madre en diciembre de 1675, atestigua Robles (I: 189) que «Domingo 22, no hubo años de la reina, porque hay cédula para que solo se celebren los del rey». En contraste, para el 6 de noviembre, Robles (I: 185) destaca la larga duración de la celebración palaciega como algo excepcional bajo el gobierno del virrey-obispo: "Se celebraron los años del rey, y hubo comedia en palacio; duró hasta las doce de la noche». La comedia quizá sería de uno de los dramaturgos espańoles aclamados posteriormente por Sor Juana misma en su Sainete segundo (Calderón, Rojas Zorrilla, Moreto) o incluso de Salazar y Torres (Hernández Araico, en prensa), de quienes empieza a seguir la pauta al iniciar su dramaturgia en loas. Esta primera de Sor Juana, incluida entre las «sueltas» por Méndez Plancarte, evidentemente precede dicha indocumentada comedia que el sorjuanista mismo señala (III: 652), deshaciendo así la propuesta errónea de que las loas profanas de Sor Juana se montaran como espectáculo dramático independiente.

Fray Payo confiaría en que solamente la jerónima podría componer un preludio que se aproximara al nivel artístico de lo que exigía la grandiosa ocasión de la mayoría de edad de Carlos II. Esta primera Loa al rey de 1675 precede, pues, la composición de sus primeros villancicos de 1676 (Tenorio 53, 56). Se puede afirmar que especialmente esta primera Loa a 
Carlos II serviría de antecedente para las comisiones de sus villancicos ${ }^{24}$, ya que en esta breve pieza teatral Sor Juana comprueba su capacidad de composición lírica para alternancias corales y sonoros ecos a base de ovillejos. También la primera Loa al rey promovería después la comisión del Neptuno alegórico, pues la jerónima exhibe aquí por primera vez su talento en manejar alusiones mitológicas y alegorías profanas ${ }^{25}$. Resaltarán las de los cuatro elementos ${ }^{26}$, sobresalientes ya como coros en la loa de 1657 de Calderón para El golfo de las sirenas (vv. 54-80, 220-235) y como parlamentos entre otras personificaciones cuatrimembres en la de 1664 de Salazar y Torres para Elegir al enemigo (vv. 280-284, 382-413) ${ }^{27}$.

En esta primera Loa al rey estrena Sor Juana la representación alegórica de los elementos que explotará a través de su trayectoria teatral. En la Loa IV al rey (1683), tres de los elementos se representan entre los dioses mitológicos Eolo, Siringa, Flora y

24. El «permiso del mismo Núñez» (Tenorio 53) podría deberse al intento de su confesor de atajar el éxito sorjuanino en homenajes monárquicos de alcance transatlántico hacia el centro del poder imperial.

25. La Loa de la Concepción con la cual Méndez Plancarte inicia el apartado de «Otras Loas» que también llama «sueltas», fechándola entre 1670-1675, se muestra casi tímida en empleo de alegorías y mitología, además que su despliegue musical no es tan frondoso como en la primera Loa al rey de 1675 .

26. Su descripción, según Amor, como «principio de todo lo criado» (v.129) y el siguiente comentario también de Amor «que la poderosa mano / de Dios a todos nos puso, / cuando nos sacó del caos» (vv. 139-141), serían la única concesión acaso religiosa en la Loa. Véase la dedicatoria o justificación de jeroglíficos y alegorías en la carta introductoria al Neptuno alegórico (firmada por la «Iglesia metropolitana de México»), en particular (66) sobre los cuatro elementos y dioses representativos.

27. Sobre los cuatro elementos corales en la loa de diciembre de 1674 del mismo dramaturgo (para El mérito es la corona, fols. 40-47), podrían haber alcanzado a llegar noticias a Sor Juana antes de componer su loa para el 6 de noviembre de 1675, quizá por la misma flota que en septiembre trae aviso de la prorrogación virreinal de fray Payo. El golfo de las sirenas de Calderón aparece primero en la Cuarta parte de comedias de Calderón de 1672 (la supuestamente corregida por Calderón es de 1674), donde se incluye además Eco y Narciso que influye sobre el auto de Sor Juana; la Tercera parte de 1664 que incluye En esta vida todo es verdad y todo mentira prologada por Sor Juana con la Loa II al rey (16811682), incluye además con respectivas loas empalmadas la zarzuela El laurel de Apolo (1658) y la ópera La púrpura de la rosa (1660), las cuales servirán de inspiración para las loas monárquicas y virreinales de la jerónima.
Pan junto con su correspondiente coro de música. Dos de los elementos se deifican en Flora y Céfiro en la Loa en las huertas para la virreina (1680-1683), así como en Neptuno y Ceres en la Loa... a la reina madre (1688-1690). En otra de las loas finales de Sor Juana (Loa a... los años del Conde de Galve, de1689) reaparecerán los cuatro elementos personificados al lado de otros cuartetos alegóricos (igual que en la Loa de Salazar y Torres para Elegir al enemigo); de modo que la representación dramática de los elementos que Sor Juana estrena en la primera Loa al rey abarca una larga trayectoria teatral.

Además de comenzar a manejar teatralmente la alegoría de los cuatro elementos en esa primera Loa a Carlos II, Sor Juana empieza a practicar la imaginería póetica-mitológica en torno particularmente al agua, la cual desplegará con maestría en el arco de entrada de 1680, tanto para alabar al nuevo virrey de afortunado título, Marqués de la Laguna, como para pedirle en el "Argumento del segundo lienzo» (125-126) su atención a obras de desagüe que redujeran la constante amenaza de inundacion del Valle de México. En la primera Loa al rey, el coro musical en off (ya no bifurcado como al principio) introduce una alabanza del poderío real marítimo: «El mar se le rinda; / pues da su potencia, / a imperios de plata, / leyes de madera» (vv. 192-195). El personaje Agua explaya así la imagen ambivalente del mar resplandeciente como plata y a la vez medio de transporte de esa riqueza americana bajo el dominio de barcos espańoles. La imagen marítima se desarrolla como vínculo del continente monárquico con el virreinal, culminando con referencia al dios mitológico del mar que predominará en el arco triunfal cinco años más tarde:

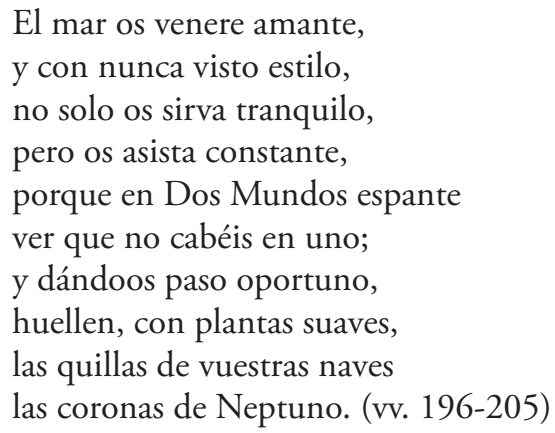

Aquí, Neptuno personifica el mar que la voz poética desea dé lugar al cruce trasatlántico del regio poderío naval. El manejo de la imaginería poética en torno al dios acuático-marítimo en esta primera Loa al rey apunta de manera embriónica a la del Neptuno 
alegórico y a la de su intervención como personaje en dos loas posteriores: la Loa al... primogénito (1684) y la Loa a... la reina madre (1688-1690).

Más adelante, en la misma primera «Loa» al rey, junto con «de la Música los ecos» (v. 144), Sor Juana estrena $^{28}$ una serie de ovillejos con los cuatro elementos al estilo de Calderón y de su «más brillante continuador», Salazar y Torres (Alatorre 1990, 656) ${ }^{29}$. La intervención del personaje Agua, alternando con ecos musicales, destaca otra vez el dominio de Carlos II sobre el mar, de nuevo identificado con el dios mitológico icónico del arco triunfal de 1680 y el personaje de las mencionadas loas cortesanas posteriores:

\begin{tabular}{|c|c|}
\hline Agua & Las que a Venus mullidas fueron plumas... \\
\hline MúsICA & $\ldots$ y espumas, \\
\hline Agua & $\ldots$ os da el mar, y en las venas que desata... \\
\hline MúsICA & . plata, \\
\hline Agua & ... con que argenta y guarnece tantas veces, \\
\hline MúsICA & ... peces, \\
\hline Agua & y en fugitivos cándidos raudales, \\
\hline Música & $\ldots$ cristales \\
\hline Agua & para que vuestras fuerzas sin iguales \\
\hline & $\begin{array}{l}\text { los términos excedan del deseo, } \\
\text { pues Neptuno os tributa por trofeo... }\end{array}$ \\
\hline MúsICA & $\begin{array}{l}\text {... espumas, plata, peces y cristales. } \\
\text { (vv. 274-283) }\end{array}$ \\
\hline
\end{tabular}

Los ecos musicales cantados por Música con los cuatro elementos en esta primera Loa al rey, en este intercambio con Agua, se dan como bi / tri-sílabos recogidos en el último verso que forma el cuarteto final de endecasílabos iniciado por el personajeelemento. García Valdés (116-117) observa el «gran efectismo sonoro» que Sor Juana logra con "los ecos de pie quebrado y el endecasílabo final donde se recogen

28. García Valdés (116) opina que Sor Juana emplea «original esquema» para la estrofa de "ovillejo en eco». Alatorre $(1990,659)$ observa que «En una composición casi seguramente anterior, la Loa de la Concepción, Sor Juana está más cerca del modelo cervantino".

29. Alatorre da el ejemplo del Baile de los elementos que «incrustó en su comedia Los juegos olimpicos» (1990, 656, n. 22), la cual no se publica hasta 1681 en la Cítara de Apolo, pero se estrena en 1673 en la corte madrileña (O’Connor 1979, 75), y ya que se documenta su montaje en el Coliseo de la Ciudad de México en 1678 (María y Campos 98), alguna copia o alguna de las ediciones sin fecha que O'Connor identifica $(1975,160)$ podrían haber llegado unos años antes a la Nueva España. en bello contraste de dispersión y recolección» ${ }^{30}$. Pero el efecto sonoro no es solo de versificación recitada, sino de toda la produccción musical sobre los oyentes de los versos cantados, tanto dentro como fuera de la Loa-personajes y auditorio. Desde esta primera Loa al rey, pues, donde Sor Juana empieza a lucir la dimensión cosustancial de la música en su teatro, cada uno de los cuatro elementos alegorizados ha salido al escenario declarando el impacto que le ha suscitado la musica coral (vv. 41-59). Es evidente entonces desde este momento termprano Sor Juana se suscribe a la imperante teoría musical de los efectos no solo propuesta por Kircher ( $\mathrm{Paz} 317)$ sino practicada por los principales dramaturgos que la jerónima emula (Hernández Araico 2012 y 2014).

En cuanto a la versificación contribuyente al efecto musical del eco, Octavio Paz vislumbra que «uno de los temas que desvelaron a Sor Juana fue el eco» (320), y considera que las loas de Sor Juana «no solo son un completo repertorio de los metros prevalescientes al finalizar el siglo XvII, sino que incluyen muchos que se usaban poco" (443), pero no menciona el verso llamado ovillejo de origen cervantino con que Sor Juana produce los ecos cantados en esta y otras loas monárquicas; ni reconoce la deuda de la jerónima con Calderón «el gran descubridor de las potencialidades dramáticas del esquema cervantino» (Alatorre 1990, 653), evidente en varios autos y además en varias de sus comedias mitológicas, como El golfo de las sirenas, La púrpura de la rosa y Eco y Narciso (Trambaioli).

A García Valdés (117), este esquema métrico del ovillejo -que solamente observa en la primera Loa al rey y en la quinta-, en esta le parece de un efectismo «apagado» por carecer de "los referentes luminosos» que destaca en varias de las otras loas al rey. Así como para la importancia de la música en estas loas monárquicas y en todo el teatro de Sor Juana no basta considerar antecedentes cortesanos de los 1620-1630, tampoco para «la obsesión por los efectos de luz» en la poesía de sus loas monárquicas basta referirse a Lope alabando a Marino y a Rubens para destacar la síntesis barroca de las artes (García Valdés 111-112, 114). Respecto a luminosidad y colorido en poesía lírica o dramática, no se puede nunca dejar de mencionar el predominio que Góngora ejercerá; en teatro, Calderón lo impondrá y, pasando por otros dramaturgos como Salazar y Torres, llega a

30. Es la misma «correlación» del teatro calderoniano explicada años atrás por Dámaso Alonso. 
Sor Juana. Respecto al símbolo del sol que García Valdés (113) y Rivera Krakowska (130) notan como sobresaliente para referirse a los monarcas en sus loas, sin duda no se origina en Sor Juana; de hecho su función -que años atrás estudió Valbuena Briones en Calderón- también sobresale en otros dramaturgos como Salazar y Torres (Farré Vidal I: 267-276). Por otro lado, toda luminosidad al nivel retórico en las loas de Sor Juana, no hay que olvidar correspondería, así como en toda fiesta cortesana, a la impresionante iluminación en el escenario, como bien se confirma en las listas de gastos de cera y bujías para representaciones palaciegas en la corte madrileña (Shergold y Varey, 59-62). Aunque la sala de comedias dentro del palacio virreinal novohispano de ninguna manera permitiera el nivel de espectacularidad del coliseo del Buen Retiro, la iluminación sí sería comparable; sin límite alguno, contribuiría grandiosamente al colorido de los trajes y maquillaje de los actores, así como al juego de luces de sus movimientos con ayuda de tramoyas, por limitadas que estas fueran.

Las loas de Sor Juana de homenaje a los reyes Carlos II, María Luisa de Orleans y Mariana de Austria constituyen, dentro de toda su obra, un corpus muy especial de teatro breve para suntuosas celebraciones de cumpleaños de la monarquía en el palacio virreinal novohispano. Consumado ejemplo del género de loas para fiestas reales, cada una marca la ocasión como día de superlativa importancia al estilo teatral de la época, equiparando monarcas a dioses mitológicos, con emotiva música cantada para un sonoro-luminoso aluvión laudatorio. La primera loa de Sor Juana a Carlos II por su importantísimo cumpleaños de mayoría en 1675 sería el première profano de la jerónima bajo el virreinato de fray Payo, cuyo éxito evidentemente la lanza a la comisión del Neptuno alegórico y numerosas obras sucesivas de encargo palaciego que incluirán las restantes loas monárquicas. En su montaje virreinal, estas funcionan como introducción a un extenso festejo teatral que -a semejanza del compendio teatral armado editorialmente en el Segundo volumen, si no celebrado tal cual, en torno a la comedia Los empeños de una casa-incluiría comedia, con su "fin de fiesta», precedido por intermedios de sainetes, incluso quizá canciones y posiblemente de Sor Juana misma, como las dos composiciones de coplas de / para música «al celebrar los años de su majestad» o «en festín de cumplimiento de años de su majestad" (Méndez Plancarte I: 94-95; 407-408).

La celebración de un natalicio real auspiciado por el Marqués de la Laguna y la Condesa de Paredes (los virreyes novohispanos de más alta nobleza y mayor proximidad al poder monárquico que ningunos anteriores) no podía ser menos que toda una fiesta grandiosa, si bien solo excepcionalmente se documenta la comedia que la loa monárquica de Sor Juana preludia. Bien se podría asumir que en medio de desastrosas guerras de creciente costo en Europa, el presupuesto virreinal no habrá bastado para continuar festejos reales anualmente; pues de los siete años y medio del virreinato del Marqués de la Laguna, solamente los primeros cuatro (16811684) se le comisiona a Sor Juana una loa para los años del rey y, antes de nacer el primogénito (1683), otra para la reina francesa María Luisa. Pero el ceso de comisiones de tales loas coincide con la dimisión del poderoso puesto de valido del hermano del virrey, el Duque de Medinaceli, en abril de1685, por no enfrentarse más con la oposición de la reina madre. Sería coincidental también que la única loa en homenaje a esta se le comisiona a Sor Juana bajo el Conde de Galve, quien, favorecido por Mariana de Austria, había colaborado en producciones teatrales con su advenedizo privado Fernando Valenzuela. Así pues, como el montaje escénico de las loas monárquicas de Sor Juana para la regia ocasión que cada una especifica se entreteje con las relaciones que los respectivos virreyespatrocinadores sostienen en la corte madrileña, paralelamente su montaje editorial por parte de la Condesa de Paredes en Inundación castálida y en el Segundo volumen, se vincularía a la compleja posición de su marido -y de ella misma- respecto a la corona, como intento de demostrar su apoyo tanto al rey como a la reina madre. La publicación de las obras de Sor Juana muy afortunadamente las salva de posible destrucción y, reafirmando su fama, logra preservarlas para la posteridad. Su alto nivel estético contribuye a prestigiar el período virreinal novohispano del Marqués de la Laguna y la Condesa de Paredes como patrocinadores de excepcional sofisticación artística y refinamiento literario comparables al de los más reconocidos poetas-dramaturgos de España. Tanto en su montaje escénico en la Nueva España como en su montaje editorial en España, las loas monárquicas configuran de manera muy privilegiada la aureola del talento lírico-teatral de Sor Juana en los círculos del más alto poder. El homenaje a la monarquía manifiesto desde su primer poema publicado resultará motivo provechoso tanto para las relaciones cortesanas de sus patrocinadores virreinales como para la fama póstuma y perdurable de la Fénix de México. 


\section{Bibliografía}

Alatorre, Antonio. «Perduración del ovillejo cervantino». Nueva Revista de Filología Hispánica, 38.2 (1990): 643-674.

Alatorre, Antonio. «En torno al Neptuno alegórico de Sor Juana». Nueva Revista de Filología Hispánica, 58.1 (2010): 269-278.

Alonso, Dámaso. «La correlación en la estructura del teatro calderoniano». Seis calas en la expresión literaria española. Madrid: Gredos, 1951: 115-182.

Arenal, Electa. «Introducción» a Sor Juana, Neptuno alegórico. Vincent Martin (ed.). Madrid: Cátedra, 2009: 9-62.

Bances Candamo, Francisco Antonio de. Teatro de los teatros de los pasados y presentes siglos. Ed. Duncan Moir. Londres: Tamesis, 1970.

Bravo Arriaga, María Dolores. «Las loas de los autos sacramentales de Sor Juana. Conciencia criolla y sentido de la composición». Serafín González y Lillian von der Walde (eds.). Palabra crítica. Estudios en homenaje a José Amezcua. México: UNAM-FCE, 1997: 250-259.

Calderón de la Barca, Pedro. Tercera parte de comedias (1664). Edición facsímil. Don W. Cruickshank y John E. Varey (eds.). London: Gregg International and Tamesis, 1973.

Calderón de la Barca, Pedro. Cuarta parte de comedias (1672) y (1674). Edición facsímil. Don W. Cruickshank y John E. Varey (eds.). London: Gregg International and Tamesis, 1973.

Calderón de la Barca, Pedro. El golfo de las sirenas. Sandra L. Nielsen (ed.). Kassel: Reichenberger, 1989.

Calderón de la Barca, Pedro. Andrómeda y Perseo. Rafael Maestre (ed.). Almagro: Museo Nacional del Teatro, 1994.

Castorena y Ursúa, Juan Ignacio de. «Prólogo a quien leyere». Fama y obras póstumas. Tomo tercero del Fénix de México y Décima Musa, poetisa de la América, Sor Juana Inés de la Cruz, religiosa profesa en el Convento de San Jerónimo de la Imperial Ciudad de México [1700]. Barcelona: Raphael Figuerò, 1701. [https://books. google.com/books?id=G3peAAAAcAAJ\&dq=prolog $\mathrm{O}+$ Castorena+Ursua+F].

Castro López, Octavio. Sor Juana Inés de la Cruz y el último de los Austrias. México: UNAM-Universidad Veracruzana, 1998.

Cotarelo y Mori, Emilio. Colección de entremeses, loas, bailes, jácaras y mojigangas desde fines del siglo XVI a mediados del XVIII. 2 vols. Madrid: NBAE, 1911.

Daniel, Lee A. «The Loa». «A Terra Incognita: Sor Juana's Theatre». Diss. Texas Tech University, 1977: 129-193.
Daniel, Lee A. «The Loa: One Aspect of the Sorjuanian Mask». Latin American Theatre Review, 16.2 (1983): 43-50.

DANiel, Lee A. «The Loas of Sor Juana Inés de la Cruz». Letras femeninas, 11 (1985): 42-48.

Daniel, Lee A. «Sor Juana's Pentad of Carlosian Loas». Luis Cortest (ed.). Sor Juana Inés de la Cruz: Selected Studies. Asunción, Paraguay: Colección de Estudios Humanísticos y Sociales, 1989: 78-87.

Daniel, Lee A. The Loa of Sor Juana Inés de la Cruz. Fredericton, Canada: York Press, 1994.

FARRÉ VIDAL, Judith. Dramaturgia y espectáculo del elogio. Loas completas de Agustín Salazar y Torres. 2 vols: I. Estudio; II. Edición. Kassel: Reichenberger, 2003.

García ValdÉs, Celsa Carmen. «Una síntesis de las artes en el barroco hispánico: las loas cortesanas de Sor Juana». Ignacio Arellano y Eduardo Godoy (eds.). Temas del barroco hispánico. Madrid: Iberoamericana, 2004: 107-127.

Hernández Araico, Susana. "Venus y Adonis en Calderón y Sor Juana: la primera ópera americana, ¿en la Nueva España?» Ysla Campbell (coord.). Relaciones literarias entre España y América en los siglos XVI y XVII. Ciudad Juárez: Universidad Autónoma de Ciudad Juárez, 1992: 137-151.

Hernández Araico, Susana. «El código festivo renacentista-barroco y las loas sacramentales de Sor Juana: Des/re/construcción del mundo europeo». Ysla Campbell (ed.). El escritor y la escena II. Actas del II Congreso de la AITENSO. Ciudad Juárez: Universidad Autónoma de Ciudad Juárez, 1994: 75-87.

Hernández Araico, Susana. "La alegorización de América en Calderón y Sor Juana: ¡Plus ultra!». Rilce, 12.2 (1996a): 281-300.

Hernández Araico, Susana. «Festejos teatrales mitológicos de 1689 en la Nueva Espańa y el Perú, de Sor Juana y Llamosas: una aproximación crítica». José Pascual Buxó (ed.). La cultura literaria en la América virreinal. México: UNAM, 1996b: 317-326.

Hernández Araico, Susana. "El montaje de El mártir del sacramento: Sor Juana y san Hermenegildo, entre jesuitas y sevillanos». Carmen Beatriz López Portillo (coord.). Sor Juana y su mundo: una mirada actual. México: Universidad del Claustro de Sor JuanaUNESCO-FCE, 1998: 254-262.

Hernández Araico, Susana. «Reivindicación de la Loa a También se vengan los dioses de Lorenzo de las Llamosas, una joya teatral virreinal». José Pascual Buxó (ed.). $L a$ producción simbólica en la América colonial. México: UNAM, 2001: 333-356.

Hernández Araico, Susana. "Amor es más laberinto: producción palaciega, ¿zarzuela parchada?» Sandra 
Lorenzano (ed.). Aproximaciones a Sor Juana. México: Universidad del Claustro de Sor Juana-FCE, 2005: 133-149.

Hernández Araico, Susana. «El teatro palaciego en la época de Sor Juana: simbiosis de espacios diversos». María Águeda Méndez (ed.). Fiesta y celebración: discurso y espacio novohispano. México: El Colegio de México, 2009: 139-156.

Hernández Araico, Susana. «Música en el teatro de Sor Juana: mímesis, mudanzas y malabarismo escénico». Iberoromania, 75-76 (2012): 205-219.

Hernández Araico, Susana. «Música y mitología en Calderón y Sor Juana: antecedentes, estrategias y propósito - materia de diálogo intertextual». Miguel Zugasti, Ester Abreu Vieira de Oliveira y María Mirtis Caser (eds.). El teatro barroco: textos y contextos. Actas selectas del congreso extraordinario de la AITENSO. Vitória: Universidade Federal do Espírito SantoAITENSO, 2014: 9-35.

Hernández Araico, Susana. «Máscaras para el manejo del espacio escénico en las comedias de Sor Juana». Sara Poot Herrera (ed.). Phoenix. 2 vols. Unidiversidad, Revista de Pensamiento y Cultura de la BUAP, 5.19 (2015): II, 64-69.

Hernández Araico, Susana. «Sor Juana y sus graciosos, III: Amor es más laberinto y el contexto novohispano de los personajes risibles en el teatro sorjuanino". Actas del XVII Congreso de AITENSO: El teatro clásico en su(s) cultura(s): de los Siglos de Oro al siglo XXI. En prensa.

Juana Inés de la Cruz, Sor. El divino Narciso. Robin Ann Rice (ed.). Pamplona: EUNSA, 2005.

JuANa InÉs DE LA CRUZ, Sor. Inundación castálida de la única poetisa, musa décima, Soror Juana Inés de la Cruz. Madrid: Juan García Infanzón, 1689. [http://www. cervantesvirtual.com/portales/ramon_lopez_velarde/ obra/inundacion-castalida-de-la-unica-poetisa-musadecima-soror-juana-ines-de-la-cruz-que-en-variosmetros-idiomas-y-estilos-fertiliza-varios-assumptos-con-elegantes-sutiles-claros-ingeniosos-utiles-versospara-ensenanza-recreo-y-admiracion--0/].

JuAna Inés de la Cruz, Sor. Obras completas de Sor Juana Inés de la Cruz. Vol. III. Autos y Loas. Alfonso Méndez Plancarte (ed.). México: Fondo de Cultura Económica [1955, 1a reimpresión], 1976.

Juana Inés de la Cruz, Sor. «Loa [para Los empeños de una casa]" y "Loa a los años del excelentísimo Señor Conde de Galve». Los empeños de una casa / Amor es más laberinto. Celsa Carmen García Valdés (ed.). Madrid: Cátedra, 2010: 109-128 y 302-328.

Juana Inés de la Cruz, Sor. «Loa [para Los empeños de una casa]" y "Loa a los años del excelentísimo Señor Conde de Galve». Obras completas de Sor Juana Inés de la Cruz. Vol. IV. Comedias, sainetes y prosa. Alberto G. Salceda (ed.). México: Fondo de Cultura Económica, 1957: 3-25 y 184-207.

Juana InÉs de la CRUz, Sor. «Loa [para Los empeños de una casa] / Prologue [for Pawns of a House]». Los empeños de una casa / Pawns of a House. Susana Hernández Araico (ed.). Michael McGaha (trad.). Tempe: Bilingual Press, 2007: 2-32.

JuAna InÉs de la Cruz, Sor. Neptuno alegórico. Vincent Martin (ed.). Madrid: Cátedra, 2009.

Juana InÉs DE LA CRUz, Sor. Segundo volumen de las obras de Soror Juana Inés de la Cruz. [Sevilla: Tomás López de Haro, 1692]. Edición facsímil. Prol. Margo Glantz. México: UNAM, 1995.

LoвAto, María Luisa. «Calderón, cisne del Manzanares. Loas cortesanas y conciencia artística». Bulletin of Hispanic Studies (Glasgow), 77 (2000): 229-262.

LoвAто, María Luisa. Loas, entremeses y bailes de Agustín Moreto. 2 vols. Kassel: Reichenberger, 2003.

Loвato, María Luisa. «Miradas de mujer: María Luisa de Orleans, esposa de Carlos II, vista por la Marquesa de Villars (1679-1689)». Judith Farré Vidal (ed.). Teatro y poder en la época de Carlos II. Fiestas en torno a reyes $y$ virreyes. Madrid: Iberoamericana, 2007: 13-44.

María y Campos, Armando de. Guía de representaciones teatrales en la Nueva España (siglos XVI al XVIII). México: Costa-Amic, 1959.

Martínez López, Enrique. «El padre Antonio Núñez, sacerdote marcial y poeta del Santo Oficio: reflexiones sobre su colaboración en Honorario túmulo de 1667 por la muerte de Felipe IV». Prolija memoria, 4.1-2 (2008-2009): 131-164.

Maura y Gamazo, Duque de. Vida y reinado de Carlos II. 3 vols. Madrid: Espasa Calpe, 1942.

Méndez Plancarte, Alfonso. "Estudio preliminar, VI. Las restantes: 'Loas sueltas' de Sor Juana». Obras completas de Sor Juana Inés de la Cruz. Vol. III Autos y Loas. México: FCE, 1976: LXXXV-LVII.

Meredith, Joseph A. "Introito and Loa in the Spanish Drama of the Sixteenth Century». Diss. University of Pennsylvania, 1928.

Neumeister, Sebastian. Mito clásico y ostentación. Los dramas mitológicos de Calderón. Kassel: Reichenberger, 2000.

O'Connor, Thomas A. «Don Agustín de Salazar y Torres: A Bibliography of Primary Sources». Bulletin of Bibliography, 4 (1975): 158-161, 167, 180.

O'Connor, Thomas A. "On Dating the comedias of Agustín de Salazar y Torres: A Provisional Study». Hispanófila, 67 (1979): 73-81.

Ortuño, Manuel. «Cerda y Aragón, Tomás Antonio de la (1638-1692)». www.mcnbiografías.com 
Paz, Octavio. Sor Juana Inés de la Cruz o Las trampas de la fe. Barcelona: Seix Barral, 1982.

Poot Herrera, Sara. «La reina se divierte: 'Loa en las huertas' de Sor Juana a la Condesa de Paredes». Judith Farré Vidal (ed.). Teatro y poder en la época de Carlos II. Fiestas en torno a reyes y virreyes. Madrid: Iberoamericana, 2007: 237-255.

Poot Herrera, Sara. «Voces, ecos y caricias en las loas de Sor Juana». Los empeños: ensayos en homenaje a Sor Juana Inés de la Cruz. México: UNAM, 1995: 167-182.

Rivera Krakowska, Octavio. «Teatro y poder en el virreinato de Nueva España: las loas profanas de Sor Juana Inés de la Cruz». Anales de Literatura Española, 13 (1999): 127-41. [Accesible en cervantesvirtual.com].

Robles, Antonio de. Diario de sucesos notables (16651703). Antonio Castro Leal (ed.). 3 vols. [1946]. México: Porrúa, 1972, 2a ed.

Ruiz Rodríguez, Ignacio. Don Juan José de Austria en la monarquia hispánica: entre la politica, el poder y la intriga. Madrid: Dykinson, 2007.

Rull, Enrique. "La teología política del barroco en una loa sacramental». Estudios sobre Calderón y el teatro del Siglo de Oro. Francisco Mundi Pedret (ed.). Barcelona: PPU, 1989: 97-107.

Rull, Enrique. «Apuntes para un estudio sobre la función teológico-política de la loa en el Siglo de Oro». Ignacio Arellano, Kurt Spang y M. Carmen Pinillos (eds.). Apuntes sobre la loa sacramental y cortesana: loas completas de Bances Candamo. Kassel: Reichenberger, 1994: 25-35.

Sabat de Rivers, Georgina. «Apología de América y del mundo azteca en tres loas de Sor Juana». Revista de Estudios Hispánicos (Universidad de Puerto Rico), 19 (1992): 267-291.

SABAT De Rivers, Georgina. "Introducción biográfica y crítica» a Sor Juana, Inundación castálida. Madrid: Castalia, 1982: 9-86.

Sabat de Rivers, Georgina. «Mujeres nobles del entorno de Sor Juana». En Busca de Sor Juana. México: UNAM, 1998: 99-130.

Salazar y Torres, Agustín de. "Loa para Elegir al enemigo». Elegir al enemigo. Thomas A. O'Connor (ed.). Binghamton, N.Y.: Studies on Spanish Classical Literature, 2002: 1-20.

Salazar y Torres, Agustín. «Loa para la comedia de $E l$ mérito es la corona y encantos de mar y amon. Judith Farré Vidal (ed.). Loas completas de Agustín Salazar y Torres. Kassel, Reichenberger, 2003: II, 380-391.

Salazar y Torres, Agustín. "Loa para la comedia del Amor más desgraciado, Céfalo y Pocris». Judith Farré
Vidal (ed.). Loas completas de Agustin Salazar y Torres. Kassel, Reichenberger, 2003: II, 321-452.

SalCedA, Alberto G. "Cronología del teatro de Sor Juana». Ábside, 17.3 (1953): 333-358.

Schilling, Hildburg. Teatro profano en la Nueva España. Fines del siglo XVI a mediados del XVIII. México: UNAM, 1958.

Shergold, Norman D. y John E. Varey. Representaciones palaciegas: 1603-1699. Estudio y documentos. Londres: Tamesis, 1982.

Sicard, Frédérique. "Condesas de Paredes: Señoras de su casa y camareras de la reina». Revista de Estudios Filológicos, 26 (2014). [Acceso en línea: http://www. um.es/tonosdigital/znum26/secciones/estudios25-condesas_de_paredes.htm\#_ftn94].

Tenorio, Marta Lilia. Los villancicos de Sor Juana. México: El Colegio de México, 1999.

ToRre Revello, José. Un catálogo impreso de libros para vender en las Indias Occidentales en el siglo XVII. Madrid: Francisco Beltrán Librería, 1930.

Toussaint, Manuel. Estudio. Loa con la descripción poética del arco que la catedral de México erigió para honrar al Virrey, Conde de Paredes. México: UNAM, 1952.

Trambaioli, Marcela. «Valores poéticos y funciones escénicas del eco en las fábulas mitológicas de Calderón». Deseo, sexualidad y afectos en la obra de Calderón. Duodécimo Coloquio Anglogermano sobre Calderón. Manfred Tietz (ed.). Stuttgart: Franz Steiner, 2001: 181-200.

Valbuena Briones, Ángel. «La palabra sol en los textos calderonianos». Perspectiva crítica de los dramas de Calderón. Madrid: Rialp, 1965: 54-69.

Varey, John E. "Andrómeda y Perseo: comedia y loa de Calderón: afirmaciones artístico-literarias y políticas». Revista de Musicología, 10 (1987): 529-545.

Velazco, Salvador. «Una loa a su majestad». Mester, 18.2 (1989): 105-113.

Zugasti, Miguel. "Loa». Diccionario de la comedia del Siglo de Oro. Frank P. Casa, Luciano García Lorenzo y Germán Vega García-Luengos (eds.). Madrid: Castalia, 2002: 198-199.

Zugasti, Miguel. «Aspectos sobre la loa y la música en el umbral de la fiesta barroca». E-Humanista. Journal of Iberian Studies, 6 (2006): 100-113. [Revista electrónica: http://www.ehumanista.ucsb.edu/sites/secure. lsit.ucsb.edu.span.d7_eh/files/sitefiles/ehumanista/ volume6/Zugasti.pdf].

Zugasti, Miguel. «Teatro y fiesta en honor del nuevo virrey: dos loas al Conde de la Monclova en Puebla de los Ángeles (1686) y Lima (1689)». Miguel Zugasti, 
Ester Abreu y M. Mirtis Caser (eds.). El teatro barroco: textos y contextos. Vitória: Universidade Federal do Espírito Santo-AITENSO, 2014: 115-167.

Zugasti, Miguel, Ester Abreu Vieira de Oliveira y María Mirtis Caser (eds.). El teatro barroco: textos y contextos. Actas selectas del congreso extraordinario de la AITENSO. Vitória: Universidade Federal do Espírito Santo-AITENSO, 2014. 
